Revista de Antropología Social

ISSN: 1131-558X

http://dx.doi.org/10.5209/RASO 56046

\title{
Espacios y tiempos de transnacionalización de la intimidad en un contexto turístico brasileño
}

\author{
Octávio Sacramento ${ }^{1}$
}

Recibido: 30 de septiembre de 2016 / Aceptado: 25 de marzo de 2017

Resumen: El espacio y el tiempo son coordinadas en función de las cuales se estructura la realidad social y, simultáneamente, elementos producidos en el marco de los ejercicios de significación, de las dinámicas relacionales y de las expresiones identitarias constitutivas de esa misma realidad. A partir de esta premisa genérica y en base a una experiencia etnográfica de investigación empírica, el artículo examina los ordenamientos espaciales y temporales de los paisajes pasionales que se establecen en el barrio turístico de Ponta Negra (Natal, nordeste de Brasil) entre las mujeres brasileñas y los turistas europeos. Se intenta entender cómo la transnacionalización euro-brasileña de la intimidad -impulsada por el turismo de masas - se inscribe y organiza en determinados segmentos topológicos y cronológicos del lugar, dándoles identidad, relieve $\mathrm{y}$, a veces, una configuración heterotópica en el escenario del barrio generadora de disonancias y de algunas tensiones sociales.

Palabras clave: Espacio-tiempo; turismo; intimidad; sexualidad; transnacionalización; Brasil/Europa.

\section{[en] Spaces and times of intimacy transnationalization in a Brazilian touristic context}

\begin{abstract}
Social reality is structured in space and time. These coordinates are, simultaneously, elements produced in the framework of practices of signification, relational dynamics, and expressions of identity embedded in that same reality. From this generic premise and based on an empirical ethnographic research, in this article, I analyze the spatial and temporal orderings of the passion landscapes that take place in the touristic neighbourhood of Ponta Negra (Natal, Northeast of Brazil) among Brazilian women and European tourists. I aim to shed light on Euro-Brazilian transnationalization of intimacy - fuelled by mass tourismand to understand the ways in which this intimacy is engraved and organized in specific topological and chronological segments of that place, providing them identity, relief, and sometimes a heterotopic configuration on the neighbourhood scenario, generating dissonances and some social tensions and disputes. Keywords: Space-time; tourism; intimacy; sexuality; transnationalization; Brazil/Europe.
\end{abstract}

Sumario. 1. Introducción. 2. Ponta Negra y sus disonancias. 3. Tiempos y espacios de transnacionalización de la intimidad. 3.1. Playa, sol y babado. 3.2. Tarde y inicio de noche en la Roberto Freire. 3.3. Balada en la plaza. 4. Consideraciones finales. Bibliografía

Cómo citar: Sacramento, O. (2017). Espacios y tiempos de transnacionalización de la intimidad en un contexto turístico brasileño, en Revista de Antropología Social 26(1), 145-163.

\section{Introducción}

"El ambiente en que comenzó la vida brasileña fue de casi intoxicación sexual. El europeo bajaba a tierra deslizándose en indias desnudas" (Freyre, 2006: 161). De

1 Universidade de Trás-os-Montes e Alto Douro; Departamento de Economia, Sociologia e Gestão; Centro de Estudos Transdisciplinares para o Desenvolvimento; Vila Real, Portugal; [octavsac@utad.pt]. 
esta forma particularmente expresiva, Gilberto Freyre señala la larga historia de tránsitos y pasiones entre Europa y Brasil en la cual se inscribe el mestizaje constitutivo de la sociedad brasileña y de su idea e identidad de nación (DaMatta, 1984; Filho, 2011). Hoy en día, la historia de encuentros pasionales euro-brasileños tiene alguna continuidad en las relaciones íntimas amorosas que los ciudadanos de ambas geografías establecen en el curso de sus desplazamientos transatlánticos de trabajo y ocio. Los flujos de personas proporcionan así múltiples posibilidades de "transnacionalización de la intimidad" (King, 2002), o sea, de constitución de configuraciones sociales afectivo-sexuales y matrimoniales que desbordan las fronteras nacionales. En el campo de las movilidades turísticas esto es muy evidente en diversos contextos brasileños, en particular en la región nordeste (Bezerra, 2010; Cantalice, 2009; Carrier-Moisan, 2008; Filho y Sardenberg, 1998; Piscitelli, 2007; Ribeiro y Sacramento, 2006; Sacramento y Ribeiro, 2013).

Es justamente uno de esos contextos que aquí se considera: Ponta Negra, un barrio playero que viene ganando proyección internacional desde finales del siglo $\mathrm{XX}$ (Furtado, 2008), presentándose como uno de los destinos más importantes y cosmopolitas de la ciudad de Natal, en el estado de Rio Grande do Norte (RN). Europa tiene una posición destacada en la emisión de los flujos turísticos internacionales hacia el barrio, constituidos sobre todo por hombres, mayoritariamente de la región mediterránea (Sacramento, 2015). Durante sus estancias es muy frecuente el establecimiento de interacciones próximas con mujeres locales - especialmente en el marco del sexo transaccional_ de las que resultan distintos vínculos de intimidad pasional, siendo muy difícil establecer una frontera clara entre las relaciones comerciales y las relaciones románticas. Aquí, como en muchos otros casos, las demarcaciones entre amor, dinero y otros "intereses" son muy dinámicas, contingentes y ambiguas (Hoefinger, 2013; Piscitelli, Assis y Olivar, 2011; Zelizer, 2005).

Teniendo en cuenta la participación de Ponta Negra en los circuitos generificados y sexualizados del turismo internacional, la discusión desarrollada en este texto se centra en los ordenamientos espaciales y temporales del barrio asociados a los paisajes pasionales euro-brasileños. El principal objetivo es entender cómo la producción de intimidades transnacionales se dispone e inscribe en las coordenadas de espacio y tiempo, gana expresión distintiva en la fisonomía y en la vida diaria del barrio y, en consecuencia, constituye escenarios sociales "transgresores" de la planificación urbana, que las autoridades locales intentan disciplinar a la luz del orden político y moral dominante. Esta comprensión permitirá, a su vez, señalar algunas de las tensiones y disensiones socio-espaciales que ahí se manifiestan, las cuales no siempre son adecuadamente consideradas en los procesos de organización y gestión de los territorios urbanos. El análisis se apoya en elementos empíricos resultantes del trabajo de campo que realicé en 2009/2010 (Sacramento, 2014) ${ }^{2}$ sobre configuraciones transnacionales de intimidad entre mujeres brasileñas y hombres europeos en el ám-

2 Este trabajo se ha beneficiado de la beca de doctorado SFRH/BD/60862/2009, de la Fundação para a Ciência e a Tecnologia (FCT, Portugal). Actualmente soy investigador del Centro de Estudos Transdisciplinares para o Desenvolvimento (CETRAD-UTAD), entidad subvencionada por fondos estructurales y de inversión europeos, en su componente FEDER, a través del Programa Operacional Competitividade e Internacionalização (COMPETE 2020) [Proyeto $n^{\circ} 006971$ (UID/SOC/04011); Referencia de la financiación: POCI-01-0145-FEDER-006971]; y por fondos nacionales a través de la FCT — Fundação para a Ciência e a Tecnologia, en el ámbito del proyeto UID/SOC/04011/2013. Aprovecho esta nota para agradecer a Luzia Oca González y a Susana Castillo Rodríguez el precioso trabajo de revisión de la traducción del texto al español. 
bito de las estancias turísticas de los últimos en Ponta Negra ${ }^{3}$. En la investigación he privilegiado un enfoque metodológico cualitativo, recurriendo a la etnografía como procedimiento orientador de un proceso de recogida de información en el que la observación participante ha asumido un papel particularmente prominente, complementada con la realización de medio centenar de entrevistas semidirigidas, la aplicación de un pequeño cuestionario para la caracterización de los turistas europeos y la recopilación de información en fuentes documentales y estadísticas. Dada la configuración transnacional de mi objeto de estudio, en una primera etapa del trabajo de campo permanecí seis meses en Ponta Negra (noviembre de 2009 a mayo de 2010) y después, mediante la adopción de una etnografía más extensiva e itinerante, estuve haciendo investigación empírica durante unos seis meses más en varios contextos geográficos (norte de Italia y Holanda) y virtuales (Internet) directamente involucrados en los flujos asociados a la constitución de vínculos transatlánticos de intimidad ${ }^{4}$.

\section{Ponta Negra y sus disonancias}

Situado en el la zona sur de la ciudad de Natal, con una población de casi 25.000 habitantes (IBGE, 2012), el barrio de Ponta Negra está formado por el antiguo poblado (vila) pesquero, también llamado Ponta Negra, algunos parques residenciales (conjuntos) y dos asentamientos precarios (Lagoinha y Pião). La vila que da nombre al barrio y desde la cual este se expandió está situada en su extremo sur, en la parte superior, plana, de una pequeña colina a alrededor de 700 metros de la ensenada de la playa de Ponta Negra. Está flanqueada por un complejo de dunas y bosque atlántico del que forma parte la célebre duna del Morro do Careca, en plena zona de protección ambiental (ZPA). El paisaje urbano y social del barrio encierra importantes contrastes entre la vila, los conjuntos y la orilla de la playa, los cuales pueden ser entendidos, siguiendo la recomendación de Santos (1994), en función de una "economía política de la ciudad" que permita desvelar sus diferentes relieves de poder y prestigio.

En la vila de Ponta Negra vive una población marcada por la destacada presencia de nativos, que es como son llamados los descendientes de la pequeña comunidad original (compuesta por indios, portugueses y africanos) y de las familias que ahí se asentaron a finales del siglo XIX, procedentes de municipios vecinos afectados por la grave sequía de 1877-1879, como fue el caso de São José de Mipibu y Nísia Floresta (Souza, 2008). Las calles, callejones y pequeñas casas edificadas sin mucha planificación que fueron reemplazando a las antiguas chozas (cabanas) evidencian la antigüedad del lugar. Algunos aglomerados residenciales circunscritos forman pequeñas vilas dentro de la vila. Las disposiciones arquitectónicas predominantes de la vivienda - casas estrechas, construidas de forma compacta, sin grandes espacios intercalares y relativamente abiertas hacia el exterior-y el modo como la gente utiliza y vive el espacio público producen un escenario de gran efervescencia social, dejando percibir una notoria fluidez entre las diferentes unidades residenciales, entre la calle y la casa, entre lo público y lo privado.

3 Aunque la intimidad sea un concepto amplio y multifacético (Constable, 2009; Jamieson, 2011), aquí es considerado de un modo más estricto para designar formas de convivencia de carácter afectivo-sexual.

4 Para un análisis detallado de las cuestiones metodológicas del trabajo de campo, en particular sobre el acceso al terreno etnográfico y la construcción gradual de la red de relaciones sociales de investigación, véase Sacramento (2016). 


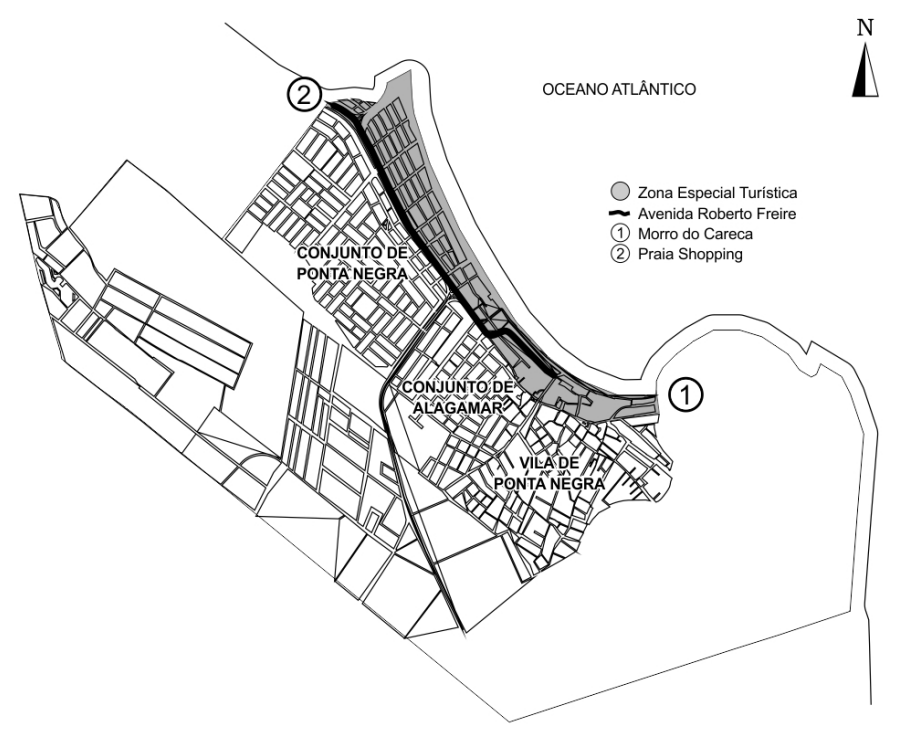

Figura 1. Estructura espacial del barrio de Ponta Negra.

La creciente afluencia de personas de fuera (chegantes) (Neverovsky, 2005) ${ }^{5}$, en su mayoría de clase media/media alta, procedentes de otras regiones de Brasil y de otros países, en particular del continente europeo, es un indicador de la reconfiguración social inducida por la actividad turística. Algunos de estos chegantes se establecen en la vila simplemente para vivir, estacional o permanentemente; otros para vivir y trabajar, y para eso compran o alquilan inmuebles a los lugareños y en ellos instalan negocios relacionados con el turismo (idem). Algunas casas con muros altos y cercas electrificadas y algunos edificios de apartamentos en condominio cerrado son señal de su presencia; una presencia que produce heterogeneidades en términos de posicionamientos de clase, de estilos de vida y de códigos culturales, y promueve la inserción de la vila en circuitos y procesos transnacionales.

A pesar de las mutaciones en curso, la carga histórica inscrita en la espacialidad de la vila le confiere aún un ambiente de tono popular y la diferencia del paisaje urbano de los conjuntos de Alagamar y de Ponta Negra (al norte) y de la franja junto a la playa (al este). En la actualidad no son solo la estructura geométrica, el espacio estandarizado y las construcciones más atomizadas de los conjuntos que contrastan con la mayor espontaneidad, sinuosidad y fluidez del paisaje edificado de la vila. Son también los habitantes, sus orígenes de clase, estilos de vida y sociabilidades. Al paisaje social más popular y burbujeante de la vila, producido por nativos y marcado por la presencia y aportes transculturales de chegantes extranjeros, se contrapone el escenario característico de las llamadas "clases medias urbanas" (Velho, 1983) de los conjuntos, de lo cual hacen

La categoría chegante incluye solo aquellos que vienen desde fuera del estado de Rio Grande do Norte y compran o alquilan inmuebles para vivir o desarrollar una actividad económica (Neverovsky, 2005). 
parte personas del estado (norte-riograndenses), algunos chegantes internacionales y muchos chegantes nacionales, procedentes mayoritariamente del sur del país (Neverovsky, 2005).

Con el proceso de urbanización turística del barrio - acompañado por su apropiación neoliberal como lugar de reproducción del capital, facilitada por las propias políticas públicas de turismo (Bursztyn, 2003; Thevenin, 2011)—, desde la década de los 90 comenzaron a aparecer construcciones en altura (espigões) con decenas de pisos en las franjas de los conjuntos, en particular en las calles adyacentes a la Avenida Eng. ${ }^{\circ}$ Roberto Freire, a pocos centenares de metros de la playa. Al mismo tiempo han abierto ahí numerosos espacios de comercio y servicios más orientados para los turistas: restaurantes, centros comerciales, unidades hoteleras, tiendas de artesanía, entre otros. Este dinamismo económico se extiende hasta el extremo sur de los conjuntos, en una zona contigua a la vila conocida como Alagamar. La oferta de restaurantes, pequeñas posadas, bares y demás espacios de diversión hacen de este contexto un polo de animación nocturna del barrio y, como veremos, una referencia de los paisajes transnacionales de intimidad, aunque presente una significativa pérdida de relevancia en los últimos años.

Por último, en el ordenamiento socio-espacial de Ponta Negra se destaca la orla de la playa, una banda de unos 400m de ancho que se extiende a lo largo de aproximadamente cuatro kilómetros, del Morro do Careca hasta el comienzo del Parque das Dunas/Via Costeira, en el límite norte del barrio. En 1987, la orla de la playa fue clasificada como zona especial turística-1 (ZET-1), lo que acabaría por impedir las construcciones en altura.

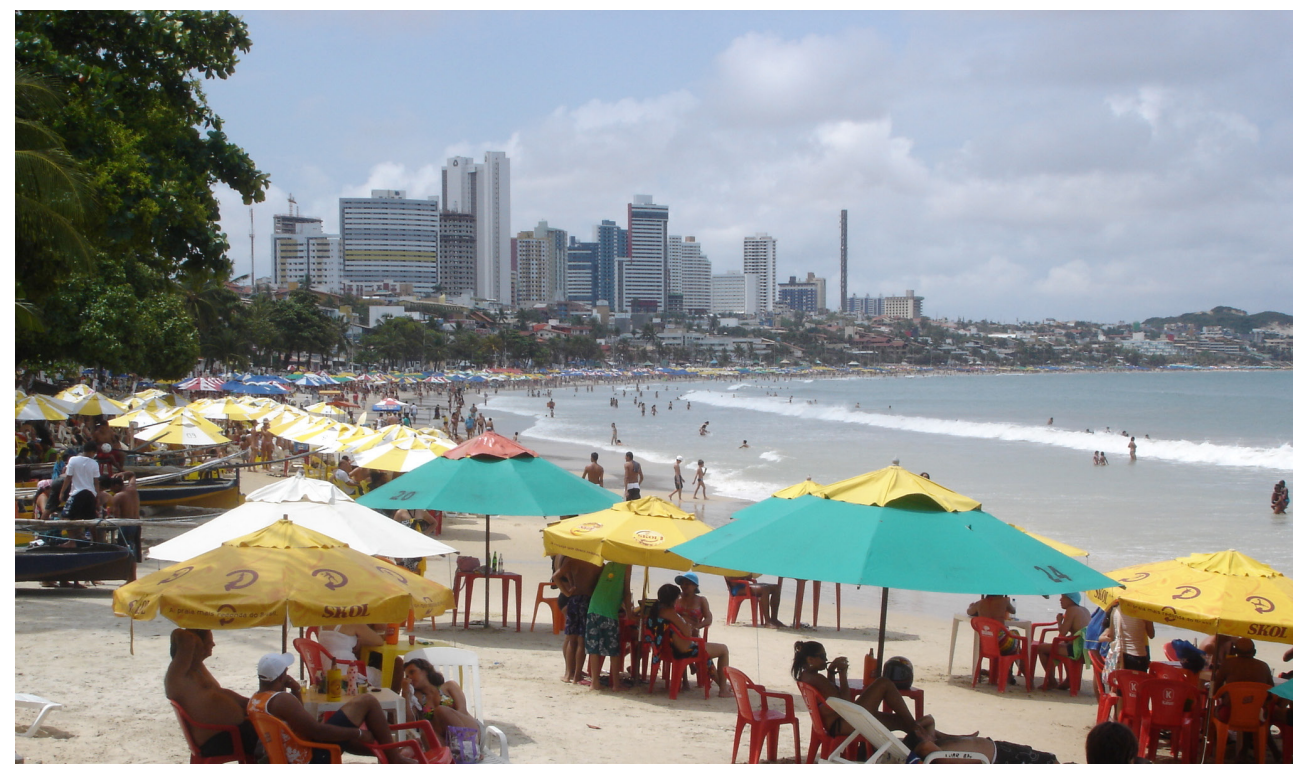

Figura 2. La orla de la playa. Al fondo, los grandes espigões residenciales.

Desde mediados hasta finales del siglo XX, la playa de Ponta Negra fue uno de los sitios preferidos por las élites locales para sus casas de veraneo (Júnior, 1997; Silva y Fonseca, 2010). Con la masificación del turismo y la estigmatización del 
lugar como territorio de gringos y garotas de programa ${ }^{6}$, muchos de los veraneantes vendieron sus residencias y se trasladaron a áreas más reservadas del litoral natalense. Al mismo tiempo se intensificó la explotación turística/comercial de la playa mediante la instalación de negocios en parcelas antes destinadas a casas de veraneo. Salvo raras excepciones, la primera línea de edificios paralela al arenal ahora está totalmente ocupada por actividades comerciales relacionadas con el turismo. En las calles de retaguardia, la implantación de estas actividades es más escasa, entremezclada con algunas viviendas y muchos complejos residenciales (v.g., apartamentos y aparthoteles) del llamado "inmobiliario turístico" (Clementino, 2009).

La playa y su entorno constituyen el epicentro del turismo de masas, de la explotación capitalista del lugar y de la presencia europea en el barrio; una presencia que se manifiesta explícitamente de las siguientes maneras: en la intensa afluencia de turistas europeos, en el número considerable de negocios desarrollados por europeos y en las muchas casas adquiridas por europeos para estancias relativamente prolongadas. El turismo y los demás procesos de internacionalización a él asociados han transformado Ponta Negra, en particular su playa, en una "touristic border zone" (Bruner, 2005): un espacio intersticial y dialógico — "empty meeting ground", en la perspectiva de MacCannell (1992) — de confluencia de escalas (local/global) y de intersección (y desvanecimiento) de fronteras entre "hosts" y "guests" (Smith, 1989), en el que emergen sociabilidades transnacionales permeadas por múltiples "idiomas relacionales" (Simoni, 2015) y nuevas formas culturales?.

Directamente impulsadas por la internacionalización turística de Ponta Negra desde finales de los años de 1990, las relaciones transnacionales de intimidad tienden ahora a ser percibidas por las autoridades locales y por amplios sectores de la sociedad natalense como marca de un estigma ("turismo sexual") que debe ser eliminado y de un modelo de turismo poco responsable y sustentable que urge abandonar. En esas relaciones, y en las fuertes tensiones y pánicos sociales que suscitan, se evidencian muchas de las complejidades, contradicciones, contiendas y volatilidades que hacen de Ponta Negra un espacio de disonancias, ampliamente deseado por la clase media local (Carrier-Moisan, 2013). El resultado es un contexto atravesado por múltiples y difusas disensiones, en el que el turismo internacional de masas tiende a entrar en conflicto con las visiones y posiciones de los sectores más acaudalados y conservadores de la sociedad local y a ser percibido como un factor de desorden moral e identitario (Sacramento, 2017). La presencia de turistas extranjeros y sus relaciones con mujeres locales generan malestar entre muchos natalenses, que parecen experimentar este escenario como una nueva invasión, una secuela de la historia colonial. Es muy común oírles decir que Ponta Negra es de los europeos (Ponta Negra é dos europeu') e identificar expresiones de ambigüedad, tensión o estigmatización

6 Gringo es un término que se utiliza un poco por toda América Latina para identificar a los extranjeros, especialmente los occidentales (Craft, 2008). Se refiere sobre todo a la categoría nacionalidad y no tanto al perfil fenotípico. La expresión garota de programa surgió en Brasil para hacer referencia a trabajadoras sexuales y, en general, a mujeres socialmente percibidas como promiscuas (Gaspar, 1985).

7 Considerando su dinamismo y potencia creativa, Bruner $(2004,2005)$ identifica la "turistic border zone" como un terreno muy fértil y un reto para la investigación antropológica. Este mismo autor se distancia incluso de un cierto prejuicio epistemológico todavía existente en las ciencias sociales que se hace eco de la idea del turismo como un fenómeno productor de una "autenticidad representada" (MacCannell, 1973), o sea, de "pseudoeventos" (Boorstin, 1992 [1961]) ubicados al margen de una supuesta esencia de la verdadera realidad social y cultural, como si hubiera dos tipos de cultura: la auténtica y la falsificada. Véase también la perspectiva de Silva (2004) acerca de los contextos turísticos como "terrenos antropológicos privilegiados". 
frente a los gringos (y sus parejas), tal como sucede en muchos otros destinos turísticos (Bezerra 2010; Simoni, 2015). La apropiación turística-capitalista de Ponta Negra, su europeización y su (re)producción como lugar de deseo (históricamente sexualizado y racializado) ha generado varias fronteras de identidad (clase, "raza", género-sexualidad, nacionalidad) que acaban por inscribirse en forma de divisiones y tensiones socio-espaciales en la propia geografía del barrio.

\section{Tiempos y espacios de transnacionalización de la intimidad}

En el ordenamiento de Ponta Negra sobresalen determinados segmentos espaciales y cronológicos (de ciclo diario y anual) claramente asociados con las expresiones euro-brasileñas de intimidad. Condicionados por los altibajos de la afluencia turística, estos segmentos están sujetos a profundas variaciones durante el año (en términos de composición y densidad social) que las instituciones y los agentes vinculados al turismo señalan y conceptualizan de la siguiente manera: temporada alta (alta estação; enero y febrero), temporada media (estação média; julio y agosto; diciembre) y temporada baja (baixa estação; marzo a junio; septiembre a noviembre). En los discursos más comunes tiende a hablarse solo en temporada alta (diciembre a febrero) y temporada baja (marzo a junio; temporada de lluvias) y, al mismo tiempo, a identificarse ciertos períodos de recuperación (julio a septiembre) y de transición (octubre y noviembre). Es común y consensual identificar el período de Navidad a Carnaval como la temporada por excelencia del turismo de sol y playa en toda la costa brasileña. A partir de ahí, la disminución de la demanda se acentúa hasta los meses de lijera recuperación, sobre todo julio y agosto, los más privilegiados para las vacaciones de verano en Europa. En temporada baja, especialmente entre abril y junio, la playa queda prácticamente vacía y el movimiento en el barrio decae de forma pronunciada. Muchas actividades informales cesan y algunos establecimientos comerciales cierran sus puertas.

En temporada alta, además de los expresivos flujos de turistas internos, el barrio recibe un apreciable flujo de turistas extranjeros, compuesto en su mayoría por hombres europeos, principalmente italianos (Sacramento, 2015). El dinamismo generado por el turismo es el gran estímulo de la afluencia femenina al barrio, a través de los puestos de trabajo que crea y por el hecho de proporcionar condiciones potencialmente atractivas al ejercicio del sexo comercial y a otros proyectos pasionales con los gringos ${ }^{8}$. La procedencia de las mujeres que participan en los espacios transnacionales de intimidad en Ponta Negra es muy diversa. Además de las locales, descendientes de las poblaciones nativas, muchas otras son provenientes de diferentes partes de la ciudad de Natal (sobre todo de la zona norte) o de sus alrededores, de varios puntos del estado de Rio Grande do Norte e incluso de estados más o menos

8 Considerados en su conjunto, estos formatos íntimos transnacionales muestran una ambigüedad que hace prácticamente imposible señalar una demarcación indudable entre el ejercicio de la prostitución por las llamadas garotas de programa y las "relaciones encantadas" (Bourdieu, 1963) de enamoramiento, noviazgo y posible conyugalidad, fundadas en ideales románticos. Podemos constatar situaciones similares en muchos otros escenarios turísticos internacionales de América Latina y del Sudeste de Asia, donde los estándares de transacción de la sexualidad son bastante fluidos y mutables, impidiendo demarcaciones estrictas entre emoción y negocio, así como una definición clara de lo que se considera prostitución (Cabezas, 2004; Cohen, 2003; Hoefinger, 2013; Kummels, 2005). 
cercanos, especialmente de la región nordeste (v.g., Paraíba, Pernambuco, Maranhão). Cuando la actividad turística disminuye, la mayoría de las mujeres que es de fuera regresa a casa para volver de nuevo a Ponta Negra después de unos meses; otras, pocas, se mudan a otros contextos que juzgan tener más movimiento (v.g., Fortaleza); otras aprovechan eventuales invitaciones de "novios" europeos para pasar una temporada en el otro lado del Atlántico.

Durante la temporada alta se hace particularmente evidente la existencia de una estructura espacio-temporal de la transnacionalización de la intimidad en Ponta Negra. En esta estructura se destacan ciertos segmentos situados en la orilla de la playa (durante el día), en la avenida Eng. ${ }^{\circ}$ Roberto Freire (en particular el Praia Shopping especialmente al final de la tarde) y en la calle Manoel de Araújo (durante la noche).

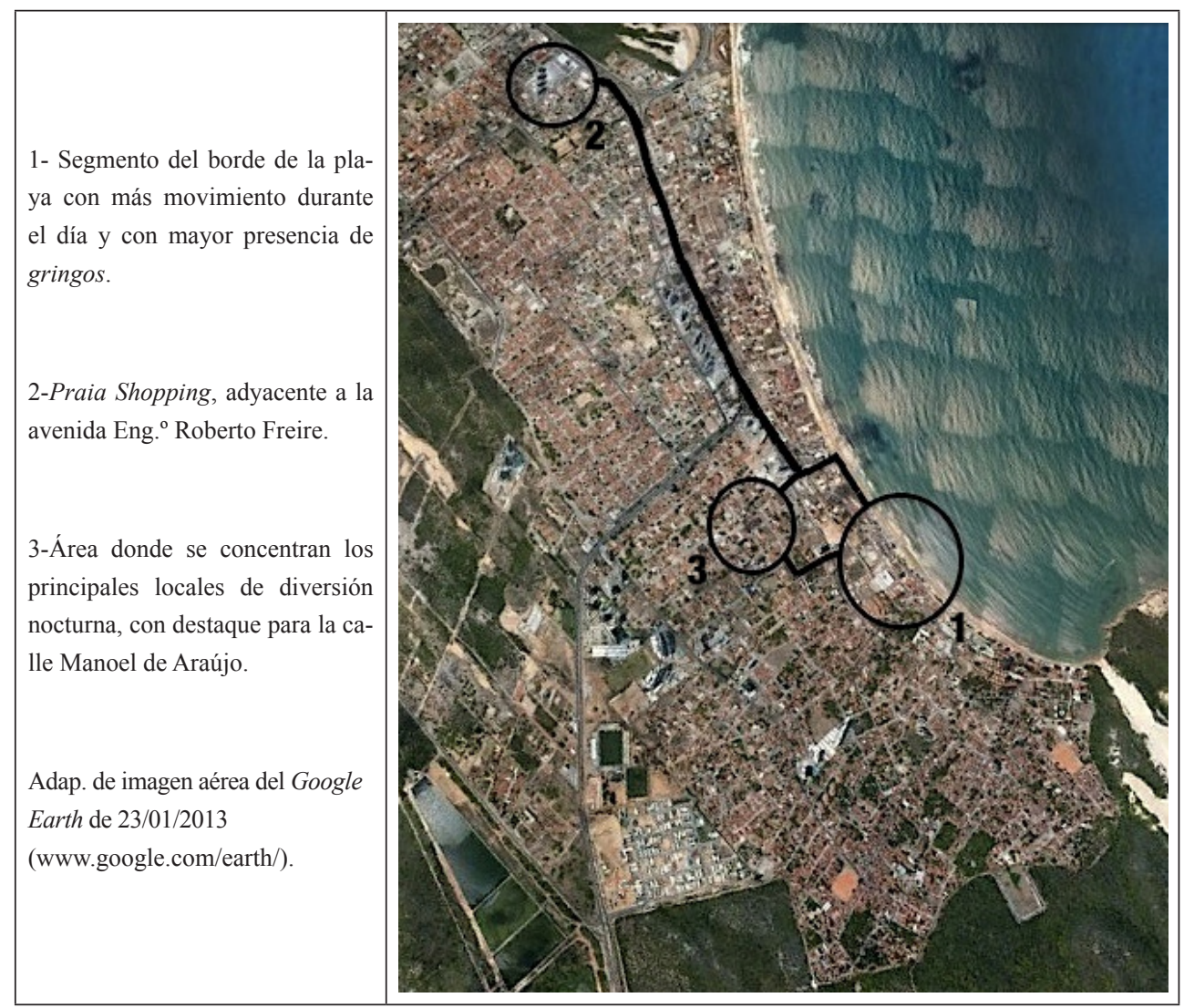

Figura 3. Espacios de referencia en la transnacionalización de la intimidad.

Veamos a continuación cada uno de los tres contextos de espacio-tiempo que más se destacan como escenarios de las relaciones íntimas transnacionales, configurando, en cierta medida, lo que Inda (2000) llama de "postnational zones": espacios permanentemente atravesados por flujos transnacionales de personas y cosas, que, al mismo tiempo, pertenecen y no pertenecen al Estado-nación. Siendo contextos de fluencias y confluencias transnacionales, estos espacios y las relaciones sociales que 
en ellos ocurren, incluso las más personales de la esfera de la intimidad, representan polos de cosmopolitismo propicios a la dialéctica de alteridad y a la construcción de diversidad cultural (Djurdjevic y Roca, 2016; Skey, 2012).

\subsection{Playa, sol y babado}

La sección correspondiente a la extensión de la calle Erivan França - situada entre los accesos rodoviarios de descenso y subida de la playa (corresponde, aproximadamente, a 1 en la figura 3) - es, durante el día, el lugar más agitado de toda la orla costera de Ponta Negra, densamente marcado por una extraordinaria profusión de flujos y sociabilidades. Aquí la concentración de turistas internacionales es bastante alta. Muchos de ellos están alojados en las numerosas unidades hoteleras existentes en las proximidades. Junto a algunos quioscos y bares, como el conocido quiosque do Cassiano y, justo delante, el complejo Mare d'Itália (hotel, restaurante y bar), la aglomeración de extranjeros es tal que, a veces, ni se oye hablar portugués. Este es el principal punto de encuentro (ponto) de turistas, semi-residentes y residentes (inmigrantes) italianos, fácilmente identificables por el registro efusivo de sus diálogos y por la inconfundible gesticulación que acompaña a la comunicación oral. Pero no solo se reúnen aquí los italianos. Justo al lado del quiosque do Cassiano, en el ponto de Rogério, paran muchos grupos de turistas escandinavos, especialmente noruegos. Algunos son clientes habituales hace más de una década. Mientras tanto fueron trayendo sus familias, amigos, amigos de amigos y sus novias o esposas, que, en su mayoría, son brasileñas a las que conocieron en Ponta Negra.

Las áreas de mayor aglomeración de gringos son, simultáneamente, las mismas que frecuentan las garotas de programa, algunos travestis y otras mujeres en busca de un novio europeo. No adelanta mucho entrar aquí en conjeturas de causalidad sobre quién atrae a quién. Con intereses relacionales recíprocos, ambas partes tienden a frecuentar los mismos espacios en horarios más o menos coincidentes. En los lugares y momentos en que se encuentran no es muy común la presencia próxima de turistas brasileños y aún menos de veraneantes de Natal de las clases privilegiadas. Estos tienden a auto-excluirse de los contextos asociados a la transnacionalización de la intimidad, socialmente construidos como lugares de desorden y, por lo tanto, sujetos a muchos atributos estigmatizantes ${ }^{10}$. Tratando de preservar las distancias y distinciones sociales (Bourdieu, 2007 [1979]), prefieren instalarse hacia el norte de la playa, cerca de la Via Costeira, o entonces veranear en las playas más exclusivas, todavía al margen de los circuitos de turismo de masas, como Muriú y Jacumã, a unos 30 kilómetros de Natal.

De este modo, coexisten dos grandes procesos antagónicos de organización socio-espacial de la playa que actúan, principalmente, según las categorías de clase,

9 Con el fin de salvaguardar el anonimato, los nombres de los establecimientos y de las personas son ficticios.

10 Aunque el estigma recae con especial intensidad en estos escenarios más circunscritos, toda la playa y, en cierto sentido, el barrio tienden a ser objeto de estigmatización, como ocurre, por ejemplo, en el barrio Praia de Iracema en Fortaleza (Bezerra, 2010). El común juego de palabras toponímico cambiando el nombre del barrio para Puta Negra condensa y evoca los fuertes estigmas que recaen sobre el contexto. Ningún otro lugar en Natal muestra de modo tan pronunciado las identidades deterioradas (Goffman, 1982) de garota de programa y de turista sexual. Se constituyen, así, como identidades territorializadas, como lo descrito por Chaves (1999) en el contexto del consumo de estupefacientes en el antiguo barrio del Casal Ventoso, en Lisboa. En este caso, el motivo social del estigma y del deterioro identitario era el consumo de drogas. En Ponta Negra son los paisajes de intimidad que superan convenciones y fronteras. 
género, sexualidad, y nacionalidad: un proceso de mestizaje, cuyo paradigma son las relaciones pasionales entre los forasteros y las mujeres locales; otro proceso de (auto)segregación, protagonizado sobre todo por ciudadanos natalenses que intentan mantener las distancias físicas y sociales en relación a los outsiders. Dicen que así evitan exponerse a ciertos comportamientos inadecuados y previenen situaciones en que la esposa o la hija puedan ser abordadas por gringos y ser confundidas con prostitutas. Estas justificaciones casi siempre expresan ciertas concepciones de las relaciones entre extranjeros y brasileñas como focos de desorden, impureza y polución social ante los cuales es imperativo crear "defensas morales" (Nahra, 2000) — por ejemplo en forma de demarcación espacial — que alejen el peligro y salvaguarden la pureza identitaria, como diría Douglas (1991).

La configuración social de la playa es bastante variable a lo largo del día. La tranquilidad del período matinal va, progresivamente, dando paso a un ambiente frenético que se mantiene hasta el final de la tarde. La mañana es destinada por los más noctámbulos a restablecer el sueño. Con la playa menos poblada, otros (sobre todo veraneantes mayores y grupos familiares) aprovechan el sol temprano de los trópicos y se establecen cómodamente en la arena o dan largos paseos junto al mar, entre la Via Costeira y el Morro do Careca. A medida que avanza el día, el ambiente se transforma. Entre el final de la mañana y las primeras horas de la tarde, en pleno pico solar, la afluencia de personas alcanza su auge. Es precisamente en este momento que llegan muchos de los/las protagonistas de las relaciones pasionales transnacionales. Con ellos y ellas, el babado ${ }^{11}$ baja a la playa. En los sitios donde normalmente se instalan, a ejemplo de los mencionados atrás, emergen intrincados escenarios sociales de performance corporal, de seducción y erotismo, de intrigas e intereses, de conflictos sentimentales y de negociación de la intimidad ${ }^{12}$. En estos escenarios, las manifestaciones emocionales son tan intensas que, a menudo, exceden los límites normativos del "descontrol controlado de las emociones" (Elias y Dunning, 1992) y desafían las reglas y ritualizaciones presentes en la vida social de casi todas las playas (Kaufmann, 1995; Löfgren, 1999; Urbain, 2002) 13. La interacción que se produce aquí entre extranjeros y mujeres brasileñas tiende a ser posicionada en el campo de la prostitución por la generalidad de los discursos hegemónicos, desde el sentido común a los discursos de políticos y académicos. No deseando de manera alguna ocultar el fenómeno de la mercantilización de la sexualidad, es fundamental, sin embargo, no tomar la parte (aunque sea la más expresiva) por el todo. No todas las relaciones se reducen a la prostitución, tal como comúnmente se entiende. En este, como en muchos otros contextos turísticos de sol y playa, las fronteras entre el

11 Designación emic para acontecimientos, rollos o chismes relacionados con la intimidad.

12 Véase Sacramento (2014: 210-229) para una perspectiva más pormenorizada de estos procesos de negociación y construcción de la intimidad, así como de la respectiva capacidad de agencia femenina.

13 En la playa de Ponta Negra, estas manifestaciones consideradas excesivas están, frecuentemente, relacionadas con comportamientos de contenido erótico-sexual, como puede constatarse en la siguiente noticia del periódico Tribuna do Norte: "Como si ya no bastasen las garotas de programa que circulan en la orla en busca de gringos, especialmente italianos, ahora las escenas explícitas de sexo llegaron a la playa, justo a medio de la tarde. [...] dos chicas, entre 18 y 20 años, decidieron mostrar sus cuerpos en un baño de mar, llamando la atención de todo el mundo. Una de ellas no se ha conformado con el baño usando un bikini de los más reducidos y decidió, primero, quitarse la parte superior, exhibiendo sus senos, en un topless. Después de unas zambullidas, la joven, sabiendo que estaba siendo observada por un grupo de turistas italianos, decidió también sacar la parte inferior. Desnuda, la chica bailaba y hacía algunos movimientos simulando un acto sexual" (Francisco, 2004: s/p). 
programa y el noviazgo de verano o otras formas de intimidad son bastante fluidas y, por lo tanto, difíciles de discernir (Piscitelli, 2001).

Con el anochecer, lo que ocurre poco tiempo después de las $17 \mathrm{~h}$, el arenal de la playa se va vaciando y la movida pasa al paseo marítimo (calçadão), en las inmediaciones del quiosque do Cassiano, y a los bares próximos, en particular al bar del complejo hotelero Mare d'Itália. Hasta el final de la tarde, este establecimiento se convierte en el contexto con mayor movimiento de la playa y el epicentro de las relaciones de intimidad de cariz más comercial. Con una configuración arquitectónica que le da una gran apertura hacia el exterior, en él pueden concentrarse cerca de cuatro decenas de garotas de programa y cien gringos en temporada alta $^{14}$. Tácitamente, hacen de este espacio más un punto de encuentro para iniciar, negociar o dar continuidad a sus relaciones. Con el avance de la tarde, empiezan a dejar el bar. Algunos salen solos, otros con las respectivas "compañeras". La mayor parte querrá, por supuesto, descansar un poco, cenar y prepararse para la noche.

En las inmediaciones la presencia policial es constante. La vigilancia está garantizada también por cámaras de vídeo instaladas a lo largo del calçadão. En 2006, cuando la vigilancia de Ponta Negra comenzó a ser discutida, el entonces secretario de turismo de Natal apuntó como objetivo principal de su proyecto la reducción de la incidencia de la prostitución en un 75\% (Tribuna do Norte, 2006). El problema para los responsables políticos y para las autoridades no es tanto la prostitución en sí misma, pues si así fuese también sería controlada en otras áreas de la ciudad; lo que parece molestarles es el hecho de que el fenómeno tenga visibilidad en el gran escaparate turístico de Natal — presentado recurrentemente como razón de orgullo de los natalenses-, a pocas decenas de metros de su ilustre símbolo turístico y cartão-postal (el Morro do Careca), y tenga gringos como principales clientes. Esta estrategia de represión de la prostitución viene ya desde finales de 2005. Desde esa época, la playa comenzó a ser objeto de redadas policiales sucesivas que culminaron en el cierre de los establecimientos nocturnos (boates) junto al arenal más connotados con el encuentro y las relaciones entre turistas y garotas de programa.

\subsection{Tarde y inicio de noche en la Roberto Freire}

Muy cerca de la playa, paralela a esta, la avenida Eng. ${ }^{\circ}$ Roberto Freire (vía principal de conexión con el centro de Natal), especialmente el segmento entre el borde marítimo y el Praia Shopping ${ }^{15}$ (fig. 1 y 3), representa una importante referencia en la cartografía de los paisajes transnacionales de intimidad en Ponta Negra. Aquí las manifestaciones pasionales tienden a ser más distendidas y sutiles que en los contextos de la playa antes mencionados y que en los locales nocturnos que se presentan más adelante. Todavía se pueden vislumbrar en su bordillo, sobre todo en la parte que pasa por el barrio de Capim Macio, pequeños focos de prostitución durante el final de la tarde y la noche ${ }^{16}$. Sin embargo, no es por eso que representa un eje central en el proceso de construcción

14 Sin embargo, es un bar convencional, similar a muchos otros en la playa, que tiene la particularidad de ser muy frecuentado por mujeres en busca de programa y por los turistas europeos, principalmente italianos. Muchos de ellos están alojados en los pisos superiores del complejo, en habitaciones a veces compartidas con "compañeras" que conocieron o reencontraron durante la estancia turística.

15 Centro comercial situado en la división de los barrios de Ponta Negra y de Capim Macio.

16 Se trata de un contexto de prostitución no propiamente orientado hacia los turistas y donde es significativa la presencia de trabajadores sexuales travestis. 
hedonista de la ciudad, como concluye Júnior (1997: 38): "rodeada de centros comerciales, restaurantes y condominios para la clase media local, esta avenida, en constante mutación, no solo expresa la urbanización turística de la ciudad, sino que también funciona como referencia para la construcción social de Natal como ciudad del placer". Muchos de los turistas extranjeros, en particular aquellos que vienen por períodos más largos, de varios meses, compran o alquilan piso en las torres residenciales adyacentes a la avenida (fig. 2) y frecuentan los numerosos espacios de consumo que en ella se encuentran. Es bastante habitual verlos acompañados por mujeres locales cenando en los restaurantes ahí localizados y haciendo compras, o simplemente paseando en el Praia Shopping, el sitio más prominente del consumismo en Ponta Negra.

Hasta las primeras horas de la noche, la orilla de la playa y el centro comercial, a pocos kilómetros, forman dos polos estructurantes del movimiento de personas en el barrio. Entre uno y otro ciertas caras y relaciones sociales se repiten. En el centro comercial es frecuente ver parejas transnacionales y grupos de turistas que también marcan una presencia asidua en la playa. Algunos de los italianos que a menudo se encuentran en el Mare d'Italia o en sus proximidades, particularmente los (menos jóvenes) que pasan grandes temporadas en Natal, también se reúnen regularmente en el Praia Shopping. A veces, al final de la tarde, se agrupan junto a la entrada principal del edificio, siendo las mujeres que pasan uno de los principales puntos de sus intereses y sociabilidades. Otros deambulan por el centro comercial, en una actitud declaradamente flaneur de consumo visual de rostros y cuerpos, buscando siempre oportunidades de conquista amorosa.

Para ellos, esta es otra ecología favorable a la negociación del acceso a la intimidad femenina y, por lo tanto, es experimentada con un cierto entusiasmo lascivo y libertino. La sexualización de que está investido el espacio es, desde luego, indiciada por los anuncios contra el llamado turismo sexual colocados en la entrada del edificio. Debido a la mayor exposición al público, resultante del ejercicio de la propia actividad profesional, las empleadas de las tiendas son las destinatarias privilegiadas de los embates pasionales de los europeos. Muchas de ellas tienen o ya tuvieron relaciones con gringos. Además de trabajar en el centro comercial, algunas también hacen, puntual o regularmente, programas durante la noche. A veces, los primeros contactos con los potenciales clientes/“compañeros" se hacen durante el horario de trabajo en las tiendas.

\subsection{Balada en la plaza}

Como resultado de la intensa "cruzada moral" (Becker, 1966) realizada por las autoridades y de la represión policial sobre los espacios más connotados con los programas, el borde marítimo de Ponta Negra fue perdiendo el movimiento nocturno y ahora queda prácticamente vacío luego a primera hora de la noche. Sin embargo, esto no significa que la represión haya sido exitosa, ya que las dinámicas sociales suprimidas junto a la playa no han cesado definitivamente. Se trasladaron unos pocos centenares de metros para el Alto de Ponta Negra ${ }^{17}$, para la calle Manoel de Araujo, más conocida como Rua do Salsa ${ }^{18}$, importante contexto de la vida nocturna (rolé,

17 A principios de 2010 ocurrió un proceso similar de reubicación de actores y dinámicas sociales con el cierre de la que fue, probablemente, la boate más asociada con la prostitución orientada para turistas en todo Brasil — la Help!, abierta desde mediados de la década de 1980 en Copacabana, en Rio de Janeiro (Menezes, 2011).

18 Este topónimo fue tomado de un reputado bar que ahí permaneció por varios años. De forma muy sugestiva, algunos natalenses también apodan la calle apodan la calle de Babilónia. 
balada, badalação) del barrio. Además de los numerosos restaurantes y lugares de diversión ya existentes en esta zona, muy frecuentados por natalenses, fueron abriendo otros que pasaron a recibir muchos de los turistas y de las garotas de programa que antes frecuentaban las boates de la playa cerradas por las autoridades. Estos nuevos establecimientos, más de una decena en total, están casi todos instalados en pequeñas fracciones contiguas, alquiladas, en la planta baja de un complejo de tiendas, propiedad de un ciudadano español. Como en la playa, muchos de los titulares del negocio son europeos, sobre todo, como hemos visto, los italianos. Casi todos están o han estado casados con mujeres brasileñas y la primera relación con Ponta Negra fue como turistas.

Con un trazado cuadrangular, el edificio forma un amplio espacio interior descubierto, similar a una pequeña plaza ${ }^{19}$, que acoge algunos quioscos de venta de bebidas y en la cual se procesa la circulación entre los diferentes bares, abiertos hasta aproximadamente las tres de la madrugada. De ahí hasta el amanecer, la balada se centra en el Pirata, una discoteca/boate aun dentro del perímetro de la plaza, muy similar a las boates que han sido cerradas en la orilla de la playa. Algunas de las caras que por aquí pasan a lo largo de la noche son las mismas que, horas antes, al final de la tarde, estaban en el Mare d'Italia, en las inmediaciones del quiosque do Cassiano o en el Praia Shopping. Otro espacio-tiempo, otro contraste social similar, fundado, desde luego, en el binomio género-nacionalidad: predominio claro de hombres europeos y de mujeres brasileñas. Sin embargo, de todos los contextos, este es aquel donde las relaciones de intimidad entre unos y otras asumen una dimensión comercial más pronunciada. La generalidad de las mujeres identifica la plaza y la noche como espacio-tiempo de trabajo sexual, una categorización que no es tan explícita para la playa y, mucho menos, para el Praia Shopping. Junto a esta categorización por parte de las mujeres, pueden aún vislumbrarse, especialmente entre los turistas, nociones sobre este contexto nocturno como un espacio-tiempo de transgresión, propicio a experiencias y expresiones de liberación del peso de las reglas y de los condicionamientos de la vida cotidiana. El tiempo de la noche tiende mismo a estar asociado a una mayor ductilidad normativa, como destaca Carrillo para México: "[la noche] Era un espacio de vida muy distintivo del tiempo del día. Las reglas eran diferentes y había una aceptación explícita para transgredir las reglas diurnas y explorar las prohibiciones veladas en la vida diaria "normal'" (Carrillo, 2002: x).

Con excepción de los nativos que acompañan a los extranjeros y de algún que otro pequeño grupo de turistas nacionales, son relativamente pocos los hombres brasileños y las mujeres europeas que frecuentan la plaza de forma asidua, a pesar de que no se paga la entrada y no hay ninguna regla de consumo mínimo (a diferencia de lo que sucede en los demás bares y pubs de la calle). La clientela femenina se compone principalmente de mujeres de Natal y de varias otras regiones de Brasil, sobretodo del nordeste, en busca de los turistas para hacer programas. De acuerdo con la mayor o menor intensidad de los flujos turísticos, muchas de estas mujeres pueden viajar a otras ciudades del nordeste brasileño y, en Natal, a veces, circulan

19 La designación de plaza (praça) piazza o piazzetta es usada a menudo por mis informantes para referirse a todo este conjunto espacial de diversión nocturna. Como alternativa también usan el nombre de uno de los bares más conocidos de allí, situado en la entrada. De ahora en adelante, paso a usar la denominación de plaza siempre que haga referencia a este contexto. 
entre la plaza y algunos night clubs de la ciudad ${ }^{20}$. En las noches más concurridas pueden pasar por la plaza más de 500 turistas, cerca de una decena de travestis y por encima de 250 garotas de programa ${ }^{21}$, mientras que en la temporada baja la afluencia de unos y de otras decae hasta apenas unas decenas. Después de que ambas partes hayan acordado el programa, el transporte a los moteles existentes cerca ${ }^{22} \mathrm{o}$, en algunos casos, a los lugares de alojamiento de los turistas es, generalmente, hecho por las decenas de taxis que hacen cola junto a la entrada de la plaza.

Debido a su formato relativamente cerrado y a las dinámicas sociales que la caracterizan, la plaza parece configurar un espacio de liminalidad (Sacramento, 2011; Turner, 1974), acantonado en el escenario más general del sistema de sociabilidades nocturnas de la Rua do Salsa y (de)marcado para identidades sexuales disidentes, que cuestionan las nociones más hegemónicas de la sexualidad (asociada a la conyugalidad y a la reproducción), de la monogamia e incluso de la heterosexualidad (Hubbard, 2001). En cierta medida se asemeja a las heterotopías de que habla Foucault (1984): espacios fuera del lugar, aunque geográficamente situados y localizables. En principio, sus clientes no se mezclan con los frecuentadores de otros establecimientos situados cerca, y viceversa. En el Forró Pé-de-Serra o en el Castelo, por ejemplo, la mayoría de la clientela está formada por jóvenes de las "clases medias urbanas" (Velho, 1983) de Natal, con capacidad para pagar la entrada y las consumiciones. En muchos casos, son los dueños de estos establecimientos los primeros en inhibir la afluencia de personas, especialmente mujeres, asociadas a la plaza y a los programas. Para eso implementan ciertas estrategias de selección para alejar potenciales clientes que — de forma algo arbitraria, por la ropa y por las maneras (jeito) _ identifican como garotas de programa. Buscan, por lo tanto, defender las demarcaciones espaciales en las cuales se inscriben las identidades de quienes no frecuentan la plaza y, al mismo tiempo, evitar la posible deterioración identitaria de sus respectivos negocios.

\section{Consideraciones finales}

Los hechos sociales están, inevitablemente, vinculados a marcos de espacio y tiempo (Harvey, 1992: 198). A lo largo del texto se ha analizado esta espacialización y temporalidad de lo social en el ámbito de las relaciones íntimas que se establecen en Ponta Negra entre las mujeres brasileñas y los turistas europeos. El análisis realizado destaca la forma como la transnacionalización euro-brasileña de la intimidad se inscribe, organiza y adquiere expresión en determinados segmentos topológicos y cronológicos locales, otorgándoles identidad, relieve y, a veces, una configuración

20 Uno de los más conocidos es el Engenho de Açúcar, ubicado en el barrio de Capim Macio, a pocos kilómetros de Ponta Negra. En este establecimiento en concreto, la prostitución es ejercida sin grandes ambigüedades entre el interés monetario y otros "intereses", asumiendo contornos mercantiles más estrictos y explícitos que en la plaza.

21 Todas o casi todas son mayores de edad. Aparentemente, hay mecanismos eficientes de control social formal ( $v . g$., video vigilancia y verificación de identidad en algunos establecimientos) e informal destinados a prevenir situaciones de explotación sexual infantil y juvenil.

22 Estos moteles son muy publicitados en la Rua do Salsa y en varios otros puntos del barrio, a través de outdoors y de anuncios pintados en las fachadas de edificios. Solo en Ponta Negra y sus alrededores hay unos 10 moteles. En la ciudad entera ascienden a más de 40. Al contrario de lo que sucede en la mayoría de los países donde hay moteles, en Brasil encierran una connotación sexual estricta, siendo destinados, específicamente, para citas amorosas. Su génesis como espacios sexuales se remonta a finales de la década de 1960 (Malta, 2008). 
heterotópica en el escenario global del barrio. Si utilizáramos un grafo ${ }^{23}$ para representar geográficamente las relaciones transnacionales de intimidad en Ponta Negra, la sección del borde de la playa entre las vías rodoviarias de descenso y subida de la orla, el centro comercial Praia Shopping y la plaza - aunque en diferentes períodos horarios - serían sus nodos (vértices) de referencia, y la calle Erivan França, la avenida Eng. ${ }^{\circ}$ Roberto Freire y la Rua do Salsa sus ejes principales (aristas) de articulación. Este mismo grafo también podría utilizarse para situar los grandes polos de la irradiación de las dinámicas de turistificación (Carrigan, 2011; Picard, 1995) y de gentrificación (Lees, Slater y Wyly, 2008; Zukin, 1995) que se extienden a casi todo el barrio, cambiando notablemente su cotidiano y fisonomía socio-espacial. De hecho, las propias relaciones afectivo-sexuales entre extranjeros y locales contribuyen a la instauración de nuevas sociabilidades, temporalidades y ritmos de vida, dinámicas identitarias y, a menudo, dejan marcas en la ordenación espacial y en el paisaje edificado del barrio. La recalificación de algunos inmuebles para vivienda o para actividad económica, por ejemplo, se realiza en el marco de los proyectos de vida común de los gringos y de sus compañeras brasileñas.

Aunque puedan ser consideradas coordenadas apriorísticas en función de las cuales se organizan y ganan sentido las estructuras, los procesos y las prácticas sociales, el tiempo y el espacio son, en simultáneo, elementos culturalmente producidos en el marco de ejercicios de significación de la realidad, dinámicas relacionales y expresiones de identidad. En Ponta Negra, como se puede concluir del análisis aquí desarrollado, se vislumbra de manera nítida la apropiación física y la construcción social - y la correspondiente investidura simbólica - de determinados espacios-tiempo como contextos paradigmáticos de manifestación de convergencias transnacionales, en los cuales se trascienden fronteras de nacionalidad y "fronteras etno-sexuales" (Nagel, 2003). De este modo, se constituyen paisajes pasionales generadores de cosmopolitismo (Djurdjevic y Roca, 2016) y de nuevas subjetividades e identidades. Estando intrínsecamente asociados a las impredecibles dinámicas del turismo playero de masas, estos paisajes en Ponta Negra evidencian una gran volatilidad socioespacial, tal como sucede en muchos otros sitios y a diversas escalas (Menezes, 2011; Piscitelli, 2004).

Desde mi salida del terreno brasileño (mayo de 2010) — y considerando la información a la cual voy teniendo acceso a distancia, a través de diversas fuentes (v.g., medios de comunicación social, Internet, antiguos informantes, informes)-, tengo constatado que los cambios han sido notables, destacándose el cierre de la plaza y la acentuada disminución de la movida en la Rua do Salsa, así como el gradual desplazamiento de los escenarios transnacionales de intimidad para fuera de Ponta Negra. Por lo tanto, y en forma de postscriptum, es importante señalar estas mutaciones en el ordenamiento del barrio, principalmente en sus segmentos más asociados a las expresiones pasionales euro-brasileñas. Directa o indirectamente, las transformaciones ocurridas derivan de su relativa pérdida de hegemonía como contexto turístico internacional de referencia en el área metropolitana de Natal. En el ámbito de los muchos impactos producidos por el mega-evento de la Copa Mundial de fútbol de 2014 (Silva, 2015) y de los problemas sociales ambientales y de infraestructuras que afectan al barrio, sobre todo su borde marítimo, (Araújo, Gomes, Freitas, y Brito, 2016), otros contextos playeros cercanos (v.g., Praia do Forte) han ganado mayor

23 Representación grafica abstracta de la realidad a través de puntos ligados por líneas. 
protagonismo y centralidad en el turismo natalense, restando densidad a los espacios y tiempos de transnacionalización de la intimidad en Ponta Negra. Estas metamorfosis en marcha en el barrio, su proceso de constitución como lugar turístico sexualizado y masificado en los últimos 20 años, las tensiones morales y sociales que lo atraviesan (y que tienen en las relaciones íntimas transatlánticas un importante foco), la diversidad cosmopolita que alberga y las asimetrías que se inscriben en su propia fisionomía nos muestran, empíricamente, aquellas que, según Neely y Samura (2011), son las características conceptuales centrales del espacio-tiempo geográfico: fluido, histórico, contestado, interaccional, relacional y configurado por diversas diferencias y desigualdades.

\section{Bibliografía}

Araújo, Maria; Gomes, Holliver; Freitas, Júlia; Brito, Maria (2016). “O turismo potiguar que chegou a perder 100 mil desembarques!”. Revista Brasileira de Pesquisa em Turismo, 10(3): 594-614.

Becker, Howard (1966). Outsiders: studies in the sociology of deviance. Toronto: Free Press.

Bezerra, Roselane (2010). “'Gringos e nativas': representações do turista estrangeiro e suas acompanhantes no bairro Praia de Iracema na cidade de Fortaleza (Ceará-Brasil)”, en Silva, M. C.; Ribeiro, F.B. (Eds.), Mulheres da vida, mulheres com vida: prostituição, Estado e políticas. Famalicão: Húmus, 205-220.

Boorstin, Daniel (1992 [1961]). The image: a guide to pseudo-events in America. New York: Vintage Books.

Bourdieu, Pierre (1963). Travail et travailleurs en Algérie. París: Mouton.

Bourdieu, Pierre (2007 [1979]). A distinção: crítica social do julgamento. Porto Alegre: Zouk.

Bruner, Edward (2004). "Tourism in the Balinese borderzone", en Gmelch, S. (Ed.), Tourists and tourism: a reader. Long Grove: Waveland Press, 219-238.

Bruner, Edward (2005). Culture on tour: ethnographies of travel. Chicago: University of Chicago Press.

Bursztyn, Ivan (2003). “A influência do ideário neoliberal na formulação de políticas públicas de turismo no Brasil”. Caderno Virtual de Turismo, 3(4): 7-12.

Cabezas, Amalia (2004). "Between love and money: sex tourism and citizenship in Cuba and the Dominican Republic". Signs - Journal of Women in Culture and Society, 29(4): 987-1015.

Cantalice, Tiago (2009). "Feminismo, mercado de sexo e turismo: reflexões sobre as múltiplas faces e interpretações do sexo mercantil”. Bagoas, 2(3): 145-178.

Carrier-Moisan, Marie-Eve (2008). "Sexo, namoro e migração: mudar de vida ou como repensar o turismo sexual no nordeste brasileiro". 26. ${ }^{a}$ Reunião Brasileira de Antropologia, 01-04 Junho, Porto Seguro-Bahia (Brasil). Disponible en: <http://www.abant. org.br/conteudo/ ANAIS/CD_Virtual_26_RBA/grupos_de_trabalho/ trabalhos/GT\%2035/marie-eve.pdf $>$ (accedido el 15/04/2011).

Carrier-Moisan, Marie-Eve. (2013). "Saving women? Awkward alliances in the public spaces of sex tourism”, en Phillips, L.; Cole, S. (Eds.), Contesting Publics: Feminism, Activism, Ethnography. London: Pluto Press, 48-75.

Carrigan, Anthony (2011). "Touristification and cultural sustainability", en Postcolonial Tourism: Literature, Culture, and Environment. New York: Routledge, 105-128. 
Carrillo, Héctor (2002). The Night is Young: Sexuality in Mexico in the Time of AIDS. Chicago: University of Chicago Press.

Chaves, Miguel (1999). "O estigma como espelho: notas sobre a deterioração de uma identidade territorializada". Fórum Sociológico, 1-2: 289-319.

Clementino, Maria (2009). "Turismo de segunda residência: europeus no Nordeste do Brasil. 2009. Disponible en: <http://www.cchla.ufrn.br/dpp/ppeur/semestres/semestres $\% 20$ anteriores/semestre-011_1/2011_1_disciplinas/topico_especiais_III/downloads_turismo _cidade /TURISMO\%20DE\%202a\%20RESIDÊNCIA.pdf $>$ (accedido el 17/12/2011).

Cohen, Erik (2003). "Transnational marriage in Thailand: the dynamics of extreme heterogamy", en Bauer, T.; McKercher, B. (Eds.), Sex and Tourism: Journeys of Romance, Love and Lust. New York: Haworth Press, 57-81.

Constable, Nicole (2009). "The commodification of intimacy: marriage, sex, and reproductive labor". Annual Review of Anthropology, 38: 49-64.

Craft, Renée (2008). ““iLos gringos vienen!’ (the gringos are coming!): female respectability and the politics of Congo tourist presentations in Portobelo, Panama". Transforming Anthropology, 16(1): 20-31.

DaMatta, Roberto (1984). O que faz o Brasil, Brasil?. Rio de Janeiro: Rocco.

Djurdjevic, Marija; Roca, Jordi (2016). "Mixed couples and critical cosmopolitanism: experiences of cross-border love". Journal of Intercultural Studies, 37(4): 390-405.

Douglas, Mary (1991 [1966]). Pureza e perigo. Lisboa: Edições 70.

Elias, Norbert; Dunning, Eric (1992). A busca da excitação. Lisboa: Difel.

Filho, Alípio S. (2011). Brésil: terre de métissages - imaginaire et quotidien dans la société brésilienne. Sarrebruck: Éditions Universitaires Européennes.

Filho, António; Sardenberg, Cecília (1998). O que é que a Bahia tem: turismo sexual e tráfico de mulheres. Salvador: CHAME/NEIM/UFBA.

Foucault, Michel (1984). "Des espaces autres". Architecture, Movement, Continuité, 5: 46-49.

Francisco, Paulo (2004). "Ponta Negra: uma praia de apelos sexuais". Tribuna do Norte, 25 Abril. Disponible en: <http://tribunadonorte.com.br/edicoesanteriores/25-4-2004> (accedido el 21/08/2005).

Freyre, Gilberto (2006 [1933]). Casa-grande e senzala: formação da família brasileira sob o regime da economia patriarcal. São Paulo: Global.

Furtado, Edna (2008). A onda do turismo na cidade do sol: reconfiguração urbana de Natal. Natal: EDUFRN.

Gaspar, Maria (1985). Garotas de programa: prostituição em Copacabana e identidade social. Rio de Janeiro: Zahar.

Goffman, Erving (1982 [1963]). Estigma: notas sobre a manipulação da identidade deteriorada. Rio de Janeiro: Zahar.

Harvey, David (1992). Condição pós-moderna. São Paulo: Loyola.

Hoefinger, Heidi (2013). Sex, Love and Money in Cambodia: Professional Girlfriends and Transactional Relationships. Abingdon and New York: Routledge.

Hubbard, Phil (2001). "Sex zones: intimacy, citizenship and public space”. Sexualities, 4: $51-71$.

IBGE (2012). Censo demográfico 2010. Rio de Janeiro: IBGE.

Inda, Jonathan (2000). "A flexible world: capitalism, citizenship, and postnational zones". PoLAR - Political and Legal Anthropology Review, 23(1): 86-102.

Jamieson, Lynn (2011). "Intimacy as a concept: explaining social change in the context of globalisation or another form of ethnocentricism?". Sociological Research Online, 16(4). Disponible en: <http://www.socresonline.org.uk/16/4/15.html > (accedido el 20/04/2017). 
Júnior, Edmilson L. (1997). A construção social da cidade do prazer: urbanização turística, cultura e meio ambiente em Natal (RN). Tesis doctoral. Campinas: Universidade Estadual de Campinas.

King, Russel (2002). "Towards a new map of European migration". International Journal of Population Geography, 8: 89-106.

Kummels, Ingrid (2005). "Love in the time of diaspora. Global markets and local meanings in prostitution, marriage and womanhood in Cuba". Iberoamericana, 5(20): 7-26.

Lees, Loretta; Slater, Tom; Wyly, Elvin (2008). Gentrification. New York: Routledge.

Löfgren, Orvar (1999). On Holiday: a History of Vacationing. Berkley: University of California Press.

MacCannell, Dean (1973). "Staged authenticity: arrangements of social space in tourist settings". American Journal of Sociology, 73(3): 589-603.

MacCannell, Dean (1992). Empty Meeting Grounds: the Tourist Papers. Londres and New York: Routledge.

Malta, Marize (2008). "Do boudoir ao motel: cultura visual, imagens decorativas e lugares íntimos para o sexo". Revista Esboços, 19: 199-215.

Menezes, Caio de (2011). "Fechamento da 'Help!': muda endereço de diversão e problemas". Jornal do Brasil, 21 Fev. Disponible en: <http://www.jb.com.br/rio/noticias/2011/02/ 21/fechamento-da-help-muda-endereco-de-diversao-e-problemas/> (accedido el 10/08/ 2011).

Nagel, Joane (2003). Race, ethnicity, and sexuality: intimate intersections, forbidden frontiers. Oxford: Oxford University Press.

Nahra, Cinara (2000). Malditas defesas morais. Natal: Cooperativa Cultural.

Neely, Brooke; Samura, Michelle (2011). "Social geographies of race: connecting race and space". Ethnic and Racial Studies, 34(11): 1933-1952.

Neverovsky, Catarina (2005). De Gata Borralheira a Cinderela: nova espacialidade decorrente do desenvolvimento turístico, diferenciada pelo estilo de vida em Ponta Negra, Natal, RN. Tesis de maestría. Natal: UFRN.

Picard, Michel (1995). "Cultural heritage and tourist capital: cultural tourism in Bali", en Lanfant, M.-F.; Allcock, J.; Bruner, E. (Eds.), International Tourism: Identity and Change. Londres: Sage, 44-66.

Piscitelli, Adriana (2001). Entre a prostituição e os namoros de Verão: género e sexualidade no contexto do turismo internacional. Rio de Janeiro: Fapesp.

Piscitelli, Adriana (2004). "El tráfico del deseo: interseccionalidades no marco do turismo sexual no Nordeste do Brasil". Quaderns-e, 4: 1-15. Disponible en: <http://www. antropologia.cat//antiga/ quaderns-e/04/04_03. htm\#4> (accedido en 14/03/2017).

Piscitelli, Adriana (2007). "Shifting boundaries: sex and money in the North-East of Brazil". Sexualities, 10: 489-500.

Piscitelli, Adriana; Assis, Gláucia; Olivar, José (Eds.) (2011). Gênero, sexo, amor e dinheiro: mobilidades transnacionais envolvendo o Brasil. Campinas: Unicamp/Pagu.

Ribeiro, Fernando B.; Sacramento, Octávio (2006). "Sexo, amor e interesse entre gringos e garotas em Natal". Cronos - Revista do Programa de Pós-Graduação em Ciências Sociais da UFRN, 7(1): 161-172.

Sacramento, Octávio (2011). "Liminal spaces: reflections on the proxemia of cross-border demand for prostitution". Space and Culture, 14(4): 367-383.

Sacramento, Octávio (2014). Atlântico passional: mobilidades e configurações transnacionais de intimidade euro-brasileiras. Tesis doctoral. Lisboa: ISCTE-Instituto Universitário 
de Lisboa. Disponible en: <file://Users/octaviosacramento/Downloads/ A-TeseDout_ Oct\%C3\%A1vio_05Junho2014.pdf> (accedido el 12/06/2015).

Sacramento, Octávio (2015). "From Europe with passion: frameworks of the touristic male desire of Ponta Negra, in the North-East of Brazil". Current Issues in Tourism, DOI: 10.1080/13683500.2015.1056517.

Sacramento, Octávio (2016). "Localizações e itinerâncias: crónica de um trabalho de campo transatlântico", en Martins, H.; Mendes, P. (Eds.), Trabalho de campo: envolvimento e experiencias em antropologia. Lisboa: ICS, 179-199.

Sacramento, Octávio (2017). "The production of tourism in Ponta Negra, Northeast Brazil: policies, representations and logics of desire". Journal of Tourism and Cultural Change (en prensa).

Sacramento, Octávio; Ribeiro, Fernando B. (2013). "Trópicos sensuais: a construção do Brasil como geografia desejada". Bagoas, 10: 215-232.

Santos, Milton (1994). Por uma economia política da cidade: o caso de São Paulo. São Paulo: Editora Hucitec.

Simoni, Valerio (2015). Tourism and Informal Encounters in Cuba. New York and Oxford: Berghahn.

Silva, Alexsandro (Ed.) (2015). Metropolização e megaeventos: impactos da Copa do Mundo 2014 em Natal-RN. Natal: EDUFRN.

Silva, Kelson; Fonseca, Maria (2010). “A produção de residência secundária no litoral oriental Potiguar - turismo e capital imobiliário". Caderno Virtual de Turismo, 10 (1): 50-63. Disponible en: <http://www.ivt.coppe.ufrj.br/caderno/index.php?journal= cade rno\&page $=$ article\&op $=$ view\&path $\% 5 \mathrm{~B} \% 5 \mathrm{D}=384 \&$ path $\% 5 \mathrm{~B} \% 5 \mathrm{D}=236>\quad$ (accedido el 14/11/2011).

Silva, Maria C. (2004). "Introdução. Por uma antropologia dos lugares turísticos", en Silva, M. C. Lisboa: Livros Horizonte (Ed.), Outros trópicos - novos destinos turísticos. Novos terrenos da antropologia. Lisboa, Livros Horizonte, 7-18.

Skey, Michael (2012). "We need to talk about cosmopolitanism: the challenge of studying openness towards other people". Cultural Sociology, 6(4): 471-487.

Smith, Valene (Ed.) (1989 [1977]). Hosts and Guests: the Anthropology of Tourism. Philadelphia: University of Pennsylvania Press.

Souza, Itamar (2008). Nova História de Natal. Natal: Departamento Estadual de Imprensa.

Thevenin, Julien (2011). "O turismo e suas políticas públicas sob a lógica do capital”. Caderno Virtual de Turismo, 11(1): 122-133.

Tribuna do Norte (2006). "Ponta Negra terá câmaras de segurança". Disponible en: <http:// tribunadonorte.com.br/noticia/ponta-negra-tera-cameras-de-seguranca/1474> (accedido el 10/08/2011).

Turner, Victor (1974). O processo ritual: estrutura e anti-estrutura. Petrópolis: Vozes.

Urbain, Jean-Didier (2002). Sur la plage: moeurs et coutumes balnéaires (XIXe-XXe siècles). Paris: Payot.

Velho, Gilberto (1983). “Aliança e casamento na sociedade moderna: separação e amizade em camadas médias urbanas”. Boletim do Museu Nacional de Antropologia, 39: 1-11.

www.google.com/earth/. (accedido el 21/01/2014).

Zelizer, Viviana (2005). The purchase of intimacy. Princeton: Princeton University Press.

Zukin, Sharon (1995). The culture of cities. Oxford: Blackwell. 